\title{
Artigo/Article
}

\section{Prevalência de rotavírus em crianças atendidas na rede pública de saúde do Estado de Pernambuco}

\author{
Rotavirus prevalence in infants and children in the public healthcare system of the State of \\ Pernambuco
}

\author{
Mariluce Lima da Silva ${ }^{1}$, Joelma Rodrigues de Souza ${ }^{1}$ e Maria Mabel Monte de Melo $^{2}$
}

\begin{abstract}
RESUMO
Introdução: Os rotavírus são considerados, importantes agentes etiológicos de gastroenterite aguda e ainda causa comum de hospitalização de crianças na faixa etária de zero a quatro anos de idade. No Brasil, a incidência de rotavírus nas crianças com gastrenterite é de 12 a 42\%, e a distribuição da infecção esta relacionada à sazonalidade que aparentemente ocorre em diferentes períodos e intensidade de acordo com a região de ocorrência. O estudo pesquisou rotavírus do grupo $\mathrm{A}$ em amostras fecais de crianças com caso suspeito atendidas na rede pública de saúde do Estado de Pernambuco. Métodos: O diagnóstico foi realizado através de ensaios imunoenzimático ELISA e teste imunoquímico de aglutinação em látex. Resultados: Foram estudadas 171 amostras. Destas, 33 (19,3\%) apresentaram positividade. Das amostras positivas $24(72,7 \%)$ eram do sexo masculino e $09(27,3 \%)$ do sexo feminino. Dentro da amostragem positiva $15,2 \%$ eram vacinadas. Quando comparamos os resultados obtidos entre o teste Elisa e aglutinação pelo Látex, houve $100 \%$ de concordância entre a positividade pelo Látex e o ELISA. Conclusões: A alta incidência desta infecção reforça necessidade de monitoramento desse vírus, definindo políticas de saúde relacionadas ao diagnóstico, profilaxia, melhores condições sócio-econômicas e aprimoramento da vacina.
\end{abstract}

Palavras-chaves: Rotavírus. Prevalência. Imunodiagnóstico.

\section{ABSTRACT}

Introduction: Rotaviruses are considered important etiological agents of acute gastroenteritis and a common cause of the hospitalization of children aged zero to four years-old. In Brazil, the incidence of rotavirus gastroenteritis in children is 12 to $42 \%$ and the distribution of infection is related to seasonality, which apparently occurs in different periods and intensity according to each region. The study investigated group A rotavirus in fecal samples of suspected children attended by the public health system of the State of Pernambuco. Methods: Diagnosis was achieved by ELISA and the Latex agglutination test. Results: Of the 171 samples studied, 33 (19.3\%) presented positivity for Rotavirus A. Among positive samples, 72.7\% belonged to male patients and $27.3 \%$ to female. Among the positive casuistic, $15.2 \%$ were vaccinated. When comparing the results obtained for the ELISA and Latex agglutination tests, 100\% agreement between positivity by Latex agglutination and ELISA was verified. Conclusions: The high incidence of this infection reinforces the need to monitor this virus and define health policies concerning its diagnosis, prophylaxis, improvement in socioeconomic conditions and the refinement of the vaccine.
\end{abstract}

Key-words: Rotavirus. Prevalence. Immunodiagnosis.

1. Laboratório de Virologia, Faculdade Maurício de Nassau, Recife, PE. 2. Setor de Virologia, Laboratório Central de Saúde Pública, Secretaria Estadual de Saúde, Recife, PE.

Endereço para correspondência: Dra. Mariluce Lima da Silva. Rua Engenho Canavieira 120, Ibura, UR-3, 51270-150 Recife, PE.

Telefax: $55813475-1196$

e-mail : maelu_torres@hotmail.com

Recebido para publicação em 01/12/2009

Aceito em 25/05/2010

\section{INTRODUÇÃO}

É significativa a relevância das infecções diarréicas no quadro de morbi-mortalidade, principalmente de crianças prematuras, populações de baixo nível socioeconômico e carente de infra-estrutura sanitária básica ou com deficiência imunológica. No que se refere à etiologia dessas infecções, destacam-se os rotavírus por suas altas taxas de prevalência nessa população ${ }^{1}$.

Descoberto por Bishop em 1973, em Melbourne, Austrália, pela identificação de partículas virais em cortes histológicos de mucosa duodenal de crianças com diarréia aguda, através da microscopia eletrônica, a denominação rotavírus foi sugerida por Flewett ${ }^{2}$, devido à semelhança morfológica desses vírus a uma roda (em latim rota). No Brasil, a primeira descrição de rotavírus em humanos ocorreu em 1976, a partir de material fecal proveniente de crianças admitidas em um hospital público de Belém, Estado do Pará3.

Os rotavírus pertencem à família dos reoviridae, do gênero rotavírus. São classificados sorologicamente em grupos, subgrupos e sorotipos ${ }^{4}$. A partícula viral completa apresenta $75 \mathrm{~nm}$ de diâmetro, morfologia esférica, simetria icosaédrica, sem envelope lipídico, contem um genoma de 11 segmentos de RNA de dupla cadeia $^{5}$. O genoma de RNA é envolvido por triplo capsídeo protéico, que codifica proteínas estruturais e não estruturais. As principais proteínas estruturais VP4, VP6 e VP7, formam a base da classificação atual dos rotavírus em 8 grupos identificados como: A, B, C, D, E, F, G e H$H^{4}$. Os rotavírus podem infectar, além do homem, outros animais, como bovinos, equinos, ovinos, sendo que os grupos A, B e C estão associados à doença no homem ${ }^{4}$, sendo mais comum os do grupo $\mathrm{A}^{5}$. O rotavírus é uma doença autolimitada, com duração entre dois a quatorze dias ${ }^{6}, \mathrm{com}_{\text {tendência a }}$ evoluir espontaneamente para a cura, o fundamental do tratamento é prevenir a desidratação e distúrbios hidreletrolíticos. A orientação atual é de manutenção da dieta alimentar normal. Eventualmente pode ser necessário recorrer à hidratação parenteral, se a oral não for suficiente. No Brasil, a vacina que faz parte 
do calendário desde março de 2006, é administrada por via oral, atenuada, monovalente (G1P1A[8]), cepa RIX4414 (VRANJAC, 2006), é indicada para proteger as crianças de seis a vinte e quatro meses, por serem mais susceptíveis às infecções por rotavírus ${ }^{6}$. Os outros grupos (D - G) não têm sido associados à doença em humanos 7 . Os rotavírus do grupo A destacam-se como os de maior importância epidemiológica ${ }^{8}$. Levantamentos epidemiológicos em escala mundial observaram a incidência de rotavírus entre 12 e $71 \%$, com média de $34 \%$ em crianças com menos de três anos de idade com diarréia aguda ${ }^{9}$. No Brasil, a incidência de rotavírus nas crianças com gastrenterite atendidas em ambulatórios ou hospitais, é da ordem de 12 a $42 \%$. Existe uma diversidade na distribuição da infecção por rotavírus no país, relacionada à sazonalidade, acontece de forma predominante no inverno em regiões de clima temperado e se faz presente por todo o ano em áreas de clima tropical. No Brasil, as regiões Sudeste, Sul e Centro-Oeste observam-se maior incidência dos rotavírus nos meses mais frios ou no período de seca entre maio a setembro, ao contrário das regiões Nordeste e Norte, onde a ocorrência de rotavírus se distribui durante todo o ano ${ }^{9}$. A infecção pelo rotavírus apresenta curto período de incubação variando de 1 a 3 dias, de um quadro leve a um quadro grave com presença de vômito, diarréia e febre alta, culminando com desidratação e podendo evoluir a óbito ${ }^{4}$. As consequências da infecção estão relacionadas à idade $\mathrm{e}$ grau de nutrição ${ }^{10}$. Em crianças até 4 meses, pode haver infecção assintomática, aventando-se a ação protetora de anticorpos maternos e do aleitamento natural. Praticamente todas as crianças se infectam nos primeiros 3 a 35 meses de vida ${ }^{4}$.

Os rotavírus eliminados em alta concentração em fezes de crianças infectadas são transmitidos pela via feco-oral, por água, alimentos e objetos contaminados, por contato pessoa a pessoa ${ }^{11}$.

O exame clínico pode sugerir fortemente a infecção pelo rotavírus, porém as manifestações clínicas da infecção não são específicas, daí a confirmação laboratorial faz-se necessária ${ }^{4}$. A detecção dos rotavírus do grupo A pode ser realizada através de reações imunoenzimáticas (ELISA), e o teste imunoquímico de aglutinação em látex com ensaios de captura de antígeno diretamente do material fecal. Os genótipos são determinados por métodos moleculares ${ }^{11}$. Os sorotipos são determinados através das proteínas (VP4 e VP7), por métodos de neutralização ${ }^{11}$. Possuem antígeno comum de grupo, localizado no componente VP6, no capsídeo intermediário, detectável pela maioria dos testes sorológicos. Esta proteína também determina o subgrupo a que pertence à cepa ${ }^{4}$.

Não há terapêutica para combater o rotavírus ${ }^{4}$, sendo que práticas dirigidas à promoção do saneamento básico e medidas de higiene se afiguram como eficácia limitada ${ }^{12}$. O impacto mundial da infecção pelo rotavírus tem conduzido ao desenvolvimento de estratégias vacinais capazes de reduzir a morbidade e a mortalidade da doença'.

Dado os altos índices de incidência e sua associação com quadros de diarréia e desidratação infantil, nosso estudo teve por objetivo identificar a soroprevalência do rotavírus A em crianças atendidas na rede púbica de Pernambuco no período de maio/2007 a setembro/2008.

\section{MÉTODOS}

\section{População e local de estudo}

O material de estudo constituiu-se de 171 amostras de fezes de crianças, atendidas pelo Sistema Único de Saúde (SUS) em unidades pediátricas dos Hospitais: Helena Moura/Tamarineira, Hospital de Pediatria Maria Cravo Gama/Afogados, Instituto Materno Infantil Prof. Fernando Figueira - IMIP/Boa Vista, Hospital da Restauração/ Derby e Laboratório Central de Saúde Pública - LACEN/Boa Vista, todos em Recife, Estado de Pernambuco, no período de maio/2007 a setembro/2008.

As amostras de fezes foram conservadas a $-20^{\circ} \mathrm{C}$. No momento do exame, foram descongeladas e preparadas segundo protocolos dos testes.

\section{Metodologia. Princípio das técnicas utilizadas}

A detecção de Rotavírus A foi realizada utilizando duas metodologias: ensaio imunoenzimático ELISA (IDEIA ${ }^{\mathrm{TM}}$ Rotavírus Ref. K6020) e o teste imunoquímico de aglutinação em látex (VIROTEC ${ }^{\mathrm{R}}$ ROTA Ref. OD038).

A metodologia ELISA utiliza anticorpos policlonais em um imunoensaio enzimático tipo sanduíche em fase sólida para detectar a presença do antígeno específico dos rotavírus do grupo A.

A metodologia látex utiliza partículas de látex recobertas com anticorpos de coelho antirrotavírus grupo A para captura do antígeno diretamente do material fecal.

\section{Análise estatística}

As fichas de notificação dos casos se encontram arquivadas no setor de Virologia do Laboratório Central de Saúde Pública LACEN/PE.

A análise dos dados obtidos das fichas epidemiológicas e a análise estatística dos resultados foi feita através do programa EpiInfo 98. A confiabilidade adotada para obtenção dos intervalos foi de $95 \%$ e o nível de significância utilizado nos testes estatísticos foi de $5 \%$.

\section{Ética}

O projeto foi submetido e aprovado pelo Comitê de Ética em Pesquisa do CISAN/PE (CAAE - 0064.0.250.000-08), protocolo 068/08, uma vez que os procedimentos atendem à Resolução no 196/96 do Conselho Nacional de Saúde (CNS).

\section{RESULTADOS}

Foram analisadas 171 amostras provenientes de crianças atendidas na rede pública de saúde do Estado de Pernambuco, no período de maio/2007 a setembro/2008.

A Tabela 1 sumariza as características demográficas das amostras analisadas no período de estudo.

Nossos resultados revelaram que dentre nossa população de estudo, a faixa etária mais afetada pela gastroenterite aguda esta compreendida entre 0-1 ano de idade.

Quando analisamos apenas o total de amostras positivas para o rotavirus $\mathrm{A}\left(\mathrm{n}^{\mathrm{o}}=33\right)$ houve maior percentual de acometimento entre as crianças do sexo masculino com predominância de diarréia como principal sintoma observado (Tabela 2).

Em relação ao período do estudo, observamos que os meses de maio a setembro registraram maiores números de infecções por rotavirus A. Entretanto, não houve diferença no número de registros quando comparamos o ano de 2008 e o mesmo período de 2007 (Figura 1). 
TABELA 1 - Dados clínicos da população amostral.

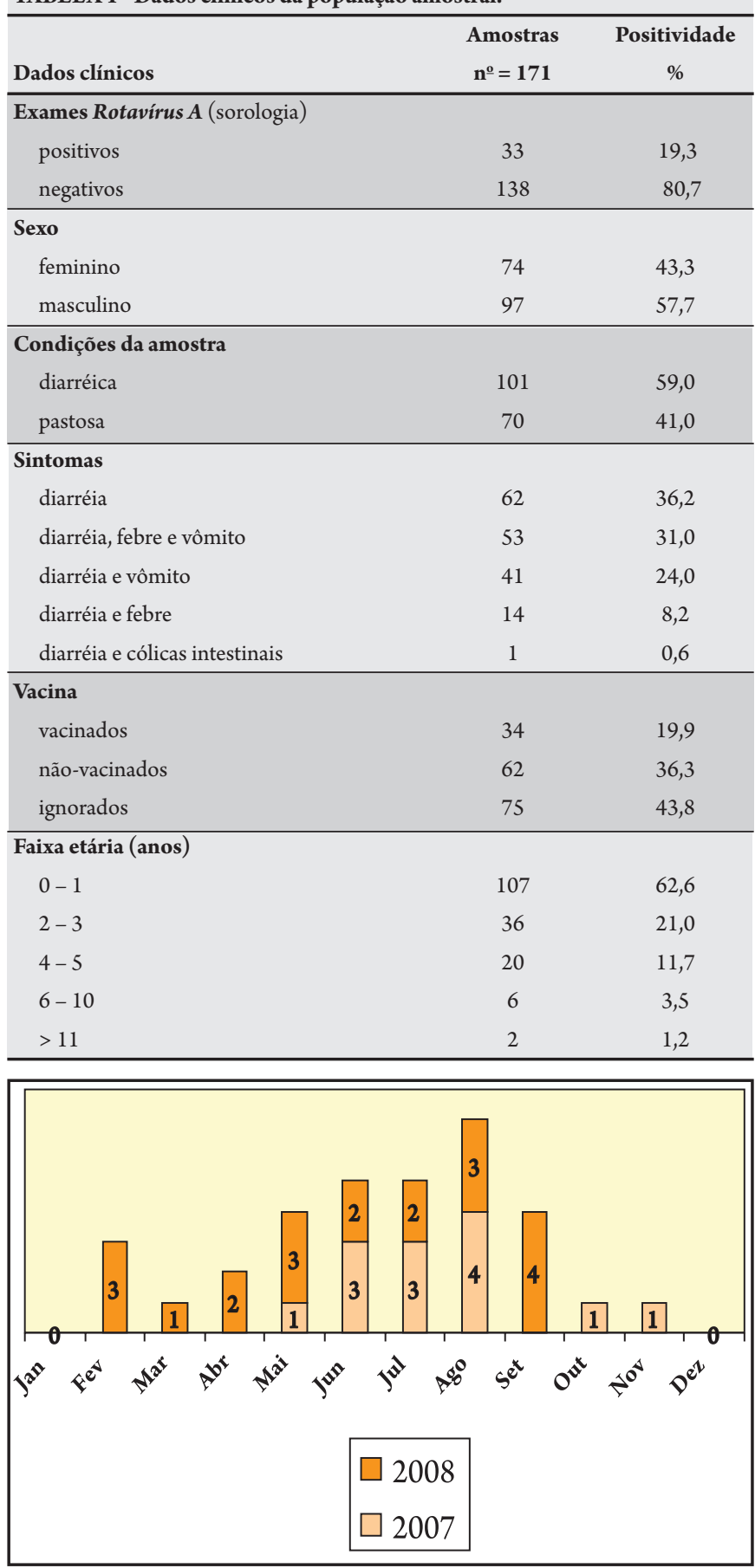

FIGURA 1 - Distribuição mensal da incidência de Rotavirus $A$, no período de maio de 2007 a setembro de 2008.

\section{DISCUSSÃo}

No presente estudo, a análise dos resultados revelou um índice de positividade de $19,3 \%$ para o rotavírus A. Esses dados corroboram com outros estudos da região nordeste, sul e centro-oeste, os quais revelaram respectivamente $24 \%, 42 \%$ e $23,2 \%$ de prevalência para o rotavírus ${ }^{14,5}$. Contudo, estudo da região sul do país revelou maior prevalência viral. Tal fato explica-se dizendo que, em regiões de clima temperado, ocorre maior incidência da infecção no inverno e no período de seca de (maio a setembro), e se faz presente ao longo do ano em áreas tropicais ao contrário das regiões nordeste e norte, onde a ocorrência de rotavírus se distribui durante todo o ano 9 .
TABELA 2 - Distribuição percentual de Rotavírus A em crianças atendidas na rede pública de saúde do Estado de Pernambuco no período de maio de 2007 a setembro de 2008 , segundo variáveis.

\begin{tabular}{|c|c|c|}
\hline Variáveis & $\begin{array}{c}\text { Amostras } \\
\mathrm{n}^{\mathrm{o}}=\mathbf{3 3}\end{array}$ & $\begin{array}{c}\text { Positividade } \\
\% \\
\end{array}$ \\
\hline \multicolumn{3}{|l|}{ Sexo } \\
\hline feminino & 9 & 27,3 \\
\hline masculino & 24 & 72,7 \\
\hline \multicolumn{3}{|l|}{ Condições da amostra } \\
\hline diarréica & 21 & 63,6 \\
\hline pastosa & 12 & 36,4 \\
\hline \multicolumn{3}{|l|}{ Sintomas } \\
\hline diarréia & 14 & 42,4 \\
\hline diarréia, febre e vômito & 6 & 18,2 \\
\hline diarréia e vômito & 13 & 39,4 \\
\hline diarréia e febre & 0 & 0 \\
\hline diarréia e cólicas intestinais & 0 & 0 \\
\hline \multicolumn{3}{|l|}{ Vacina } \\
\hline vacinados & 5 & 15,2 \\
\hline não vacinados & 10 & 30,3 \\
\hline ignorados & 18 & 54,5 \\
\hline \multicolumn{3}{|l|}{ Faixa etária (anos) } \\
\hline $0-1$ & 21 & 63,6 \\
\hline $2-3$ & 9 & 27,3 \\
\hline $4-5$ & 2 & 6,1 \\
\hline $6-10$ & 1 & 3,0 \\
\hline$>11$ & 0 & 0,0 \\
\hline
\end{tabular}

Neste estudo, quando se considera as crianças com sorologia positiva para rotavírus A, $24(72,7 \%)$ são do sexo masculino e 9 (27,3\%) do sexo feminino, observou-se uma diferença estatística significativa a qual discorda com o resultado obtido por ${ }^{5,14}$ os quais relataram não haver diferenças estatísticas significativas em seus estudos. Uma eventual explicação para esta diferença seria a exposição física da criança.

A caracterização morfológica das fezes não evidenciou nenhum traço especial, para detecção do rotavírus, sendo de um modo geral, de consistência diarréica ${ }^{13}$.

$\mathrm{Na}$ análise geral da eficácia da vacina, observamos que 19,9\% das crianças com infecção diarréica aguda eram vacinadas contra rotavírus e dentro da amostragem positiva, 15,2\% eram vacinadas. Segundo Bricks cols ${ }^{7}$, as doenças diarréicas podem ser causadas por diversos vírus, como: adenovírus, astrovírus, etc, para os quais a vacina contra rotavírus não oferece proteção. Outros fatores podem interferir na efetividade da vacina como: condição nutricional, infecções mistas, diversidade de sorotipos e subtipos, emergência de novas cepas (mutações ou reagrupamento genético), etc.

No que respeita à distribuição etária e sintomatologia, nos resultados positivos, foi observado que a infecção por rotavírus A ocorreu de forma sintomática em todas as faixas etárias o que corrobora com os estudos de Andreasi cols ${ }^{5}$ e Costa cols ${ }^{9}$ onde evidenciou-se que a faixa etária acometida variou, de acordo com a região, nível socioeconômico e período de realização dos estudos. O presente estudo discorda de pesquisas que afirmaram em seus estudos, que em crianças até 4 meses pode haver infecção assintomática, devido a ação protetora de anticorpos maternos e do aleitamento natural. Uma eventual explicação para a presença da sintomatologia nessa faixa etária de (0 - 4 meses), seria o desmame precoce e o grau de nutrição das crianças ${ }^{4,14}$. 
Quando comparado os resultados obtidos entre o teste ELISA e aglutinação pelo látex, houve $100 \%$ de concordância entre a positividade pelo látex e o ELISA.

Com este estudo, podemos afirmar que a região nordeste possui sazonalidade, pois verificou-se um aumento de positividade no período compreendido de maio até setembro. $\mathrm{O}$ sexo masculino foi o mais atingido e de um modo geral as fezes se apresentaram de consistência diarréica e com sintomatologia em todas as faixas etárias. Mesmo vacinadas, fatores interferiram na efetividade da vacina. Laboratórios de pequeno porte podem utilizar o teste em látex como alternativa no diagnóstico do rotavírus ${ }^{10}$.

Os resultados encontrados nesta pesquisa, somados aos descritos por outros autores, sugerem a necessidade contínua de monitoramento desse vírus, bem como de outros vírus associados a doenças diarréicas e estudos de genotipagem do rotavírus circulante, o que vai fornecer informações para o aprimoramento da vacina em uso no Brasil, como também um melhor estudo para a avaliação da eficácia da vacina.

\section{AGRADECIMENTOS}

A Deus pelas bênçãos sem fim. As minhas orientadoras: Maria Mabel e Joelma Souza, pelo incentivo.

\section{CONFLITO DE INTERESSE}

Os autores declaram não haver nenhum tipo de conflito de interesse no desenvolvimento do estudo.

\section{SUPORTE FINANCEIRO}

Laboratório Central de Saúde Pública vinculado à Secretaria Estadual de Saúde do Estado de Pernambuco.

\section{REFERÊNCIAS}

1. Santos RV, Linhares AC, Coimbra-Jr CEA. Estudos epidemiológicos entre grupos indígenas de Rondônia: IV. Inquérito sorológico para rotavírus entre os Suruí e Karitiána. Rev Saude Publica 1991; 25:230-232.

2. Flewett TH, Bryden AS, Davies H. Virus particles in gastroenteritis. Lancet 1973; 2:1497.

3. Linhares AC, Pinheiro FP, Schmetz C, Muller G, Peters D. Duovirus (rotavirus) em Belém do Pará, (nota prévia). Rev Inst Med Trop São Paulo 1977; 19:278-279.

4. Secretaria de Estado de Saúde de São Paulo. Coordenadoria dos Institutos de Pesquisa. Manual das Doenças Transmitidas por Alimentos e Água: Rotavírus. Disponível em http://www.cve.saude.sp.gov.br/htm/hidrica/IF_63ROTA.htm (acessado em 3 set 2008).

5. Andreasi MSA, Batista SMF, Tozetti A, Ozaki CO, Nogueira MM, Fiaccadori FS, et al. Rotavírus A em crianças de até três anos de idade, hospitalizadas com gastroenterite aguda em Campo Grande, Estado do Mato Grosso do Sul. Rev Soc Bras Med Trop 2007; 40:411-414.

6. Araújo TME, Dantas JM, Carvalho CEF, Costa MAO. Surto de Diarréia por Rotavírus no Município de Bom Jesus/PI. Disponível em: http://www. abrasco.org.br/cienciaesaudecoletiva/artigos/artigo_int.php?id_artigo=1166 (acessado em 22 de out. 2008).

7. Bricks LF. Rotavírus: atualização sobre doenças e vacinas. Pediatria (São Paulo) $2005 ; 27: 252-266$

8. Vranjac A. Vacina Contra Rotavírus. Rev Saude Publica 2006; 40:355-358.
9. Costa PSS, Cardoso DDP, Grisi SJFE, Silva PA, Fiaccadori F, Souza MBLD, et al. Infecções e reinfecções por Rotavírus A: genotipagem e implicações vacinais. J Pediatr (Rio J) 2004; 80:119-122.

10. Silveira WC. Desenvolvimento de teste rápido para detecção de rotavírus: imunoensaio de captura e aglutinação em látex. [dissertação]. [Rio de Janeiro]: Instituto Oswaldo Cruz; 2005.

11. Vranjac A. Diarréia e Rotavírus. Rev Saude Publica 2004; 38:844-845

12. Linhares AC. Epidemiologia das infecções por rotavírus no Brasil e os desafios para o seu controle. Cad Saude Publica 2000; 16:629-646.

13. Baldacci ER, Candeias JAN, Breviglieri JC, Grisi SJE. Etiologia viral e bacteriana de casos de gastroenterite infantil: uma caracterização clínica. Rev Saude Publica 1979; 13:47-53.

14. Cunha SC, Cunha L, Favarin ME. Prevalência de resultados positivos para rotavírus, em exames realizados no laboratório de análises clínicas UNISUL, no período de Janeiro a dezembro de 2006. Disponível em http://junic.unisul. br/2007/JUNIC/pdf/0091.pdf (acessado em 22 de out. 2008).

15. Costa PSS, Grisi SJFE, Cardoso DDP, Fiaccadori FS, Souza MBLD, Santos RAT. Manifestações clínicas e epidemiológicas das infecções por Rotavírus A. Pediatria 2004; 26:151-158. 